¿Una CGT para el Frente Popular democrático y antifascista? El Partido Comunista de la Argentina y el movimiento sindical durante la Segunda Guerra Mundial

Hernán CAMARERO

Avances del Cesor, V. XVII, № 22, junio 2020, pp. 149-171.

ISSNe 2422-6580 / ISSN 1514-3899 - http://web2.rosario-conicet.gov.ar/ojs/index.php/AvancesCesor/index

\title{
¿Una CGT para el Frente Popular democrático y antifascista? \\ El Partido Comunista de la Argentina y el movimiento sindical durante la Segunda Guerra Mundial
}

\section{A CGT for the democratic and anti-fascist Popular Front? The Communist Party of Argentina and the union movement during World War II}

Hernán Camarero Instituto de Historia Argentina y Americana Dr. Emilio Ravignani

Universidad de Buenos Aires Consejo Nacional de Investigaciones Científicas y Técnicas

hercamarero@gmail.com (Argentina)

Recibido: $13-05-2019$

Aceptado: 16-09-2019

Publicado: 05-06-2020

\section{Resumen}

En este artículo nos proponemos un examen de la relación del Partido Comunista argentino con la Confederación General del Trabajo (CGT) entre 1937 y 1943, es decir, los años previos y de primer desarrollo de la Segunda Guerra Mundial. Es un período clave para entender los intentos comunistas de aplicación de la estrategia del "Frente Popular" en los perímetros de la organización gremial, lo cual permite pensar acerca 
de sus verdaderas condiciones de realización y de los contextos en los que se desplegó semejante empresa política. Este estudio no sólo pretende aportar un mayor conocimiento de la actuación del comunismo en el área gremial sino también a iluminar la relación que esta fuerza tuvo con las otras corrientes del movimiento obrero con las que intentaba coalicionarse o confrontar, como el sindicalismo y el socialismo. Hubo una bibliografía que refirió a esta presencia comunista en el movimiento sindical, aunque en escasa medida sobre estos recortes temporales y temáticos específicos. Aún es necesario profundizar el trabajo de reconstrucción de este proceso, en especial, de las caracterizaciones y posiciones del PC en función de su objetivo de alcanzar la dirección del movimiento obrero.

Palabras Clave: comunismo, movimiento obrero, Argentina, frente popular

\begin{abstract}
In this article we propose an examination of the relation of the argentine Communist Party with the General Confederation of Labor (CGT) between 1937 and 1943, that is, the previous and firts years of the Second World War. It is a key period to understand the communist attempts to apply the strategy of the "Popular Front" in the perimeters of the trade union organization, which allows us to think about its real conditions of realization and the contexts in which such a political enterprise was deployed. This study not only aims to provide a greater understanding of the performance of communism in the trade union area but also to illuminate the relationship that this force had with the other workers movement with which it tried to coalition or confront, such as syndicalism and socialism. There is a bibliography that referred to this communist presence in the trade union movement, but whitout these specific temporary and thematic cuts. It is still necessary to deepen the work of reconstructing this process, in particular, of the characterizations and positions of the $\mathrm{CP}$ in terms of its objective of achieving the leadership of the workers movement.
\end{abstract}

Keywords: Communism, workers' movement, Argentina, popular front.

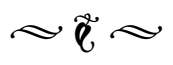

\section{Introducción}

El Partido Comunista (en adelante, PC) de la Argentina, emergido como corriente interna del socialismo en la década de 1910 y fundado como organización con aquel nombre en diciembre de 1920, al calor de la Revolución Rusa, buscó una implantación firme en el movimiento sindical desde sus inicios (Camarero, 2017). Durante esta última década, los comu- nistas avanzaron en su inserción en el mundo de los trabajadores, a través de la creación de las células de militantes en fábricas y talleres, de agrupaciones gremiales, de diversas asociaciones de carácter socio-cultural y, por supuesto, desde su actuación en el nivel político. Sin embargo, la presencia del PC en las estructuras dirigentes del movimiento sindical no fue fácil de asegurar. Los afiliados del partido siempre habían tenido participación en los consejos 
de dirección de las centrales obreras durante los años veinte y treinta, pero estaban en una situación claramente minoritaria frente a la posición hegemónica que tenían los cuadros provenientes de la tradición sindicalista revolucionaria y, en menor medida, de los socialistas. En efecto, tanto en la Federación Obrera Regional Argentina (en adelante, FORA) IX Congreso (1915-1922), como en su continuadora Unión Sindical Argentina (en adelante, USA) (1922-1930), ambas de tendencia sindicalista, pero también en la Confederación Obrera Argentina (en adelante, COA) (19261930), que agrupaba a los cuadros obreros del Partido Socialista (en adelante, PS) y a otros dirigentes también sindicalistas, los comunistas debieron conformarse con activar a nivel de base o ejercer el control de algunos gremios y federaciones, pero quedaron muy lejos de poder influir en la orientación global de aquellas centrales (Camarero, 2007 y 2018).

Este aislamiento o debilidad del PC en los niveles de conducción del gremialismo se mantuvo en los inicios de la Confederación General del Trabajo (en adelante, CGT), la sigla más importante del movimiento obrero argentino antes del peronismo, constituida en septiembre de 1930, como producto de la unificación de las antes mencionadas USA y COA. Los comunistas no ingresaron en su seno en su primer lustro, pues se hallaban imbuidos en la línea de "clase contra clase", propia del "Tercer Período" de la Internacional Comunista (en adelante, IC), que detrás de una orientación confrontacionista y sectaria, virtualmente impidió la posibilidad de intervenir en las organizaciones laborales reformistas por parte de los partidos comunistas en todo el mundo (Hájek, 1984; Carr, 1986). En función de ello, habían conformado en 1929 el Comité de Unidad Sindical Clasista (en adelante, CUSC), una suerte de central rival a la CGT, acusada por ellos de "burocrática, colaboracionista y progubernamental” (Camarero, 2013). En verdad, más allá del carácter aislacionista que el PC experimentaba en sus prácticas políticas y sindicales, la relación del conjunto de la izquierda política, no sólo de ese partido, con la CGT fue conflictiva. En la central predominaban los miembros del sindicalismo, que propugnaban un perfil apolítico, prescindente y hostil a la acción conjunta con los partidos obreros, tanto el PC como el PS, a pesar de que con militantes de este último debían convivir en la misma entidad (García, 2017).

Hacia 1935 la situación en el interior de la CGT sufrió un cambio significativo. A fines de ese año ocurrió una ruptura de esa organización, cuando un sector importante del más tradicional elenco sindicalista acabó fuera de la dirección y constituyó otra entidad: la CGT Catamarca (que dos años después acabó reorganizándose bajo la denominación USA). Desde ese momento, el grueso de la CGT (durante un tiempo conocida bajo el aditamento "Independencia", por el nombre de la avenida donde tenía su sede), quedó en manos de militantes del PS y algunos otros sindicalistas. Hacia allí se dirigió el PC, que ahora abandonaba la línea de "clase contra clase" y adoptaba la estrategia del "Frente Popular". Este viraje se institucionalizó en el VII y último congreso de la IC, reunido en julio-agosto de aquel año y la sección argentina lo adoptó de inmediato (Fascismo, democracia y frente popular. VII Congreso de la Internacional Comunista, 1984; Claudín, 1970; Broué, 1997). Ahora se propiciaba una política de amplio acuerdo democrático, antifascista y antimperialista, lo que conducía a los comunistas a disolver sus organismos sindicales "clasistas revolucionarios" o "rojos" y a ingresar o fusionarse con los existentes y de 
carácter mayoritario, liderados por corrientes "reformistas". Esto llevó a la disolución de la Internacional Sindical Roja (Tosstorff, 2018). Bajo este nuevo marco de referencia, los sindicatos en manos de los comunistas decidieron su ingreso pleno a la CGT. Sin embargo, en los años siguientes, la nueva dirección cegetista fue redefiniendo su alineamiento, recuperando las tradicionales concepciones antipolíticas y de prescindencia ideológica. Ello se manifestó no sólo en los cuadros de tradición sindicalista que habían permanecido en la organización tras la ruptura con el otro sector en 1935, sino en gran parte de los militantes que formalmente pertenecían al PS, pero que en la práctica se mostraban reacios a toda tutela partidaria y a imprimir a su acción una dinámica política, prefiriendo sostener la más irrestricta autonomía sindical y equidistancia de los dos grandes partidos de la izquierda en ese momento, el PS y el PC (Ceruso, 2017a; 2017b). Los cuadros orgánicos de estos últimos comenzaron a colisionar con esta orientación de la central desde 1936-1937.

Estas tendencias a la confrontación entre los dos bloques en el ámbito de la CGT no hicieron más que profundizarse en los años 19391943. Pero esta fuerte disputa incorporó nuevos ejes de debates, en torno al posicionamiento a adoptar frente a la Segunda Guerra Mundial. Durante estos cuatro años, el PC hizo una nueva consideración acerca de la interna gremial y de la correlación de fuerza entre las distintas corrientes, en el marco de los cambios que ocurrían a nivel nacional e internacional, derivados de la gran conflagración bélica mundial. Los comunistas venían aumentando su presencia entre los sindicatos industriales y de la construcción, las organizaciones que más se expandían, por el crecimiento de esa rama de la economía. La conclusión que extrajeron en ese entonces era que estaba abierta la posibilidad de alcanzar la dirección del movimiento obrero y de la propia CGT. Pero era un paso que debía estar al servicio de orientar a dicha central en las perspectivas del "Frente Popular", arrastrando a los socialistas hacia esa política y combatiendo al sector sindicalista que se oponía a todo compromiso político en ese sentido. La guerra, sin embargo, introdujo variables específicas, convirtiendo a esta experiencia en un proceso convulsivo, que tuvo como algunos de sus eventos claves a los congresos cegetistas de 1939 y 1942. Y que concluyó en una nueva escisión de la CGT a comienzos de 1943, cuando ésta volvió a quedar dividida en las llamadas " $\mathrm{N}^{\circ} 1$ " y " $\mathrm{N}^{\circ}$ 2": la primera, reclamando independencia de los partidos; la segunda, propiciando acuerdos con éstos y explícitos pronunciamientos políticos en pos de una coalición democrática antifascista.

Considerando todo este contexto recién enunciado, en este artículo nos proponemos un examen detenido de esta relación del PC con la CGT entre 1939 y 1943, en continuidad con las indagaciones que hicimos sobre los ciclos previos (Camarero, 2015). Es un período clave para entender los intentos comunistas de aplicación de la estrategia del "Frente Popular" en los perímetros de la organización gremial, lo cual permite pensar acerca de sus verdaderas condiciones de realización y de los contextos en los que se desplegó semejante empresa política. Para desenvolver nuestra interpretación partimos de algunas constataciones. Ellas nos indican que, desde el momento en que los militantes del PC ingresaron a las filas de la CGT, hacia 1935-1936, tuvieron como objetivo principal el de orientarla hacia un perfil más comprometido con el "Frente Popular". Dentro de la central obrera, esta línea colisionó con la mayoría de la conducción, conformada 
por una alianza de antiguos cuadros sindicalistas, dirigentes ferroviarios y, sobre todo, varios de los cuadros gremiales del propio socialismo, autonomizados del control partidario. Dicha coalición dirigente tendió a reafirmar las viejas concepciones de conciliación de clases y las posiciones antipolíticas, prescindentes y "sindicalistas" que habían sido características de la primera CGT (1930-1935). Nuestra hipótesis es que el PC, si bien impugnó esta concepción, mostró dificultad para dar curso a una propuesta de superación de ella, debido a la naturaleza de la propia estrategia de "Frente Popular" postulada por el partido, proclive a un acuerdo con los sectoresantifascistas, incluso, los provenientes de la pequeña y mediana burguesía, "nacional y progresista". El objetivo era extender el campo de alianzas para sumar a todos ellos a la política de la Unidad Nacional y del apoyo a los países que combatían el nazifascismo, en particular, la Unión de Repúblicas Socialistas Soviéticas (en adelante, URSS). Si bien es cierto que esta línea no implicó que el PC renunciara a promover la organización y las luchas obreras, favoreció una cierta "conciliación de clases" en la práctica y en el discurso, aunque en una variante distinta a los planteamientos "colaboracionistas" del sindicalismo. Lo que este último espacio propiciaba desde el sindicato e interpelando directamente al aparato ejecutivo del estado, los comunistas lo postulaban a partir de un proyecto de unidad política programática entre central gremial y partidos obreros junto a expresiones de la burguesía democrática.

Este estudio no sólo pretende aportar un mayor conocimiento de la actuación del comunismo en el área gremial sino también a iluminar la relación que esta fuerza tuvo con las otras corrientes del movimiento obrero con las que intentaba coalicionarse o confrontar (aunque limitando el análisis exclusivamente a las perspectivas del PC). Hubo una bibliografía que refirió a esta presencia comunista en el movimiento sindical, aunque en escasa medida sobre estos recortes temporales y temáticos específicos (Aricó, 1979; del Campo, 1983; Godio, 1989; Korzeniewicz, 1993; Iñigo Carrera, 2000; Di Tella, 2003; Horowitz, 2004; Camarero, 2007; Ceruso, 2015). Aún es necesario profundizar el trabajo de reconstrucción de este proceso, en especial, de las caracterizaciones y las posiciones con las cuales el PC buscó alcanzar la dirección del movimiento obrero. En función de ello, entre otras fuentes, priorizamos el exhaustivo análisis de las páginas del periódico partidario Orientación. ${ }^{1}$

\section{El comunismo \\ frente a la dirección de la CGT antes de 1939}

Cuando los comunistas ingresaron en la CGT, entre 1935 y 1936, sus expectativas frente a la central obrera eran muy grandes. Consideraban que ahora sí, tras los años de estrategia apolítica, neutralista y "prescindente" impulsada por los sectores más ortodoxamente sindicalistas, comenzaría un período de más cabal posicionamiento político de la organización,

1. Orientación comenzó a editarse en septiembre de 1936, aunque en sus primeros cuatro números apareció bajo otro nombre, el de Hoy. Tuvo una aparición regular, como quincenario en una primera época, y luego como semanario, hasta el golpe de junio de 1943. Este órgano periodístico permite una reconstrucción privilegiada de los lineamientos generales del PC, y también de los que específicamente el partido adoptó hacia el movimiento obrero. Desde 1940 el PC también editó un diario La Hora, que, junto a las informaciones cotidianas, reeditaba las caracterizaciones y posturas de Orientación. Por eso, en este artículo nos hemos concentrado en este último medio de prensa. 
que la ubicaría como uno de los puntales del deseado "Frente Popular" democrático y antifascista. La causa del antifascismo se había convertido en un asunto de primero orden dentro del campo político, dentro del cual el $\mathrm{PC}$ podía comulgar ampliamente con el PS y otras corrientes y asociaciones civiles (Bisso, 2000 y 2007). Esas expectativas duraron poco. Desde 1937 los comunistas fueron advirtiendo que, dentro de la CGT, el grupo de los ferroviarios y de los cuadros afines a las concepciones sindicalistas del apoliticismo y la prescindencia (a pesar de que muchos de ellos eran afiliados al PS), volvieron a ganar terreno y a abroquelarse, frente a los militantes claramente adheridos al PS y al PC. A partir de marzo, los comunistas cuestionaron a esos sectores "prescindentes" y al curso que le imprimían a la central obrera. Uno de los principales dirigentes sindicales del PC, Rubens Iscaro, sostuvo entonces que la CGT había sido pasiva frente al curso reaccionario del gobierno de Agustín P. Justo (1932-1938), expresado en el fraude cometido en las elecciones de Santa Fe y en el intento por imponer un candidato para los comicios presidenciales. ${ }^{2}$ Reconocía avances sustanciales desde los hechos de diciembre de 1935, "que acabaron con una camarilla al servicio de los peores intereses, entronizada en la dirección de la CGT, trabando el camino hacia la unidad y el desarrollo de la central". Y denunciaba que la central se había alejado de los pronunciamientos políticos y de las luchas populares por las libertades.

La CGT ratificó el camino de la prescindencia en ocasión del $1^{\circ}$ de mayo de 1937. El PC se apresuró a lanzar una serie de consignas para

2. Iscaro, R. (3 de marzo de 1937). La CGT se ha desviado de su camino". Orientación, p. 2. Archivo Histórico del Partido Comunista de la Argentina, Buenos Aires.

154 lo que entendía que debía ser una gran manifestación proletaria:

Por el triunfo del Frente Popular español, contra la reacción fascista. Por la paz en el mundo, contra sus saboteadores. Por el radicalismo al poder, con Alvear presidente. Contra la carestía de la vida, por la rebaja del alquiler y el aumento de los salarios. Por el Frente Popular argentino, en defensa de la libertad democrática, contra las 50 familias vacunas. ${ }^{3}$

Sin embargo, a diferencia del año anterior, la CGT se negó a organizar un acto o marcha en conjunto con los partidos, mostrando que quería mantener la equidistancia con ellos. Los comunistas, frente a la realidad de que no existiera un acto unitario, si bien descargaban las culpas sobre el resto de los partidos que habían rechazado la idea del encuentro unitario, hacían responsable a la dirección de la CGT. ${ }^{4}$ Finalmente, parte de los sindicatos enrolados en la CGT, los dirigidos por el PC, sin la participación de la dirección de la central ni la adhesión oficial de ésta, organizaron una marcha en la Capital, que confluyó en un acto en la Plaza San Martín.

Completados los trámites estatutarios de la CGT, en junio de 1937 el sector más "apolítico" logró un éxito importante: la elección de José Domenech como nuevo secretario general (cargo que ocupó durante los siguientes seis años), respaldado en una sólida presencia en el Comité Central Confederal (en adelante, CCC) y en la Comisión Administrativa (en adelante, CA), las flamantes denominaciones que adquirían los máximos organismos de

3. $i^{\circ}$ de Mayo! (10 de abril de 1937). Orientación, p. 1.

4. ¡Unidad contra el fascismo! (26 de abril de 1937), Orientación, p. 1. 
conducción colegiada de la central. En el nuevo $\mathrm{CCC}$ de junio, formado por 45 integrantes, la Unión Ferroviaria (en adelante, UF) poseía 18 de ellos, es decir, el 40\%. Era esta organización gremial la que continuaba teniendo la llave del control de la central y la que la orientaba al camino de la prescindencia política. Desde ese momento el PC pudo acceder a espacios en la conducción de la CGT:dentro del CCC pasó a ocupar el $16 \%$ de sus cargos, expresados por los tres representantes del Sindicato de Obreros Albañiles, Cemento Armado y Anexos de la Capital, que ya se había convertido en Federación Nacional de la Construcción (en adelante, FONC), y otros cuatro provenientes del Sindicato Obrero de la Industria Metalúrgica (en adelante, SOIM), el Sindicato Unitario de Obreros de la Madera (SUOM), la Federación Obrera de la Industria de la Carne (en adelante, FOIC) y la Federación Obrera del Vestido (en adelante, FOV). Militantes del PC llegaron a la conducción: Pedro Chiarante se convirtió en miembro de la Comisión Administrativa, y Mauricio Rybak y José Peter empezaron a actuar como vocales.

La dirección de la CGT Independencia se tornaba cada vez más autónoma para rechazar las influencias o presiones partidarias. ${ }^{5}$ Asimismo, la central se convertía en una entidad de masas, consolidandosu control sobre la estructura sindical del país. La FORA anarquista había quedado reducida a una expresión acotada. Varios de los sindicatos que habían quedado fuera de la CGT tras el "golpe" de diciembre de 1935 terminaron ingresando a sus filas. Restaba la competencia de la CGT Catamarca. Pero su debilidad fue tan grande que acabó disolviéndose como tal y, luego de unirse con algunos

5. Un análisis general de esta dinámica, en: Cheresky (1984, pp. 147-199). gremios autónomos, decidió formar una nueva central, que adoptó un nombre familiar al sindicalismo, el de Unión Sindical Argentina. $\mathrm{Su}$ Congreso Constituyente, al que asistieron unos cuarenta sindicatos, casi todos de existencia más bien nominal, se efectuó en mayo de 1937.

La posición de los comunistas dentro de la CGT, en tanto, se volvía bifronte. Por un lado, criticaban a los dirigentes que sostenían las posiciones prescindentes. Por otro, intentaban mostrarse como fieles soldados de la causa cegetista y favorables a un acuerdo con aquel sector, cada vez que éste se viera dispuesto a convocar a la lucha reivindicativa. En este sentido, el PC, desde fines de 1937 apoyó la campaña lanzada por la conducción de la CGT, con actos públicos en todo el país, por un Plan de Emergencia, el cual incluía la defensa de la jornada máxima de 40 horas semanales, el seguro nacional a la desocupación, ancianidad e invalidez, las vacaciones pagas y la instauración de comisiones de estudio de salarios, entre otras consignas. ${ }^{6}$

Como expresión de ese intento de "modus vivendi", aún pudo ser posible que el $1^{\circ}$ de mayo de 1938 se realizase un acto unitario en la $\mathrm{Ca}^{-}$ pital Federal (sobre la Diagonal Norte) en el que participaron la CGT, el PS, el Partido Socialista Obrero (PSO, un desprendimiento por izquierda del socialismo) y el PC, pero no la Unión Cívica Radical y el Partido Demócrata Progresista, dos fuerzas que sí lo habían hecho en el acto de 1936. Los oradores pautados fueron Domenech y Camilo Almarza como

6. La Confederación General del Trabajo iniciará una campaña nacional por el Plan de Emergencia (18 de septiembre de 1937), Orientación, p. 3; ¡Apoyemos entusiastamente la campaña de la CGT por el plan de emergencia! (10 de febrero de 1938), Orientación, p. 3. 
secretario general y adjunto de la CGT, Luis V. Sommi por el PC, Francisco Pérez Leirós como secretario de la Comisión Organizadora, y Américo Ghioldi, Nicolás Repetto y Mario Bravo por el PS. ${ }^{7}$ Los comunistas llegaron al acto con un discurso unitario: "La unidad es la fuerza y la victoria de la clase obrera. La división es su debilidad y su ruina". ${ }^{8}$ La concentración fue multitudinaria, con casi cien mil participantes, según los organizadores. Dos meses después, esta concordia se consolidó, con la realización de una reunión del CCC, que convocó para junio de 1939 al postergado I Congreso Ordinario de la CGT. El PC saludó este paso, que permitiría la definitiva normalización de la central y su propio reforzamiento como corriente, pues estarían en condiciones estatutarias de ingresar en la conducción de la misma. ${ }^{9}$

No obstante, las concepciones de prescindencia no hicieron más que ganar terreno en la conducción de la CGT, deseosa de autonomizarse más de los partidos y ceñir su actividad al camposindical. Todo ello alimentaba los disensos con los cuadros obreros de los partidos. En parte esto fue ayudado por la pérdida de la fortaleza parlamentaria del PS, que hasta 1936 contaba con un bloque de 43 diputados en el Parlamento y en los cuatro años anteriores había logrado impulsar una veintena de leyes de carácter laboral y social. Pero en aquel año, levantada la abstención electoral de la UCR, el número de diputados socialistas cayó a 25 y para 1939 sólo eran 5. No casualmente, en

7. La manifestación unitaria del $1^{\circ}$ de mayo será grandiosa (22 de abril de 1938), Orientación, p. 1.

8. Por España y por nuestras libertades. Todos unidos en este $1^{\circ}$ de mayo (29 de abril de 1938), Orientación, p. 1.

9. Dirigentes de la CGT opinan sobre el último C. Confederal (7 de julio de 1938), Orientación, p. 2.

156 esos años se redujo drásticamente el interés del Congreso Nacional por la cuestión laboral y casi no hubo sanción de leyes sobre el tema. Por otra parte, el PC se hallaba virtualmente imposibilitado de obtener presencia legislativa $\mathrm{y}$, de hecho, de presentarse legalmente a elecciones. Todo ello hizo perder atractivo, dentro de la CGT, al intento de colaboración con los partidos de izquierda e hizo crecer la alternativa de los sectores más volcados a las concepciones sindicalistas.

Había una suerte de mandato por imponer estas posturas, lo que también convulsionaba al gremio ferroviario. En junio de 1938, el Congreso de la UF expresó claros pronunciamientos a favor de la nacionalización de los ferrocarriles y la suspensión de las retenciones sobre el salario, que fueron apoyados por los comunistas. Pero allí sobrevino una grave crisis de la organización: el sector más sindicalista de la UF, liderado por Luis M. Rodríguez, cuestionó el pedido que hizo la dirección del sindicato para que el Parlamento interviniera en sus reclamos sobre las empresas ferroviarias. Finalmente, la facción de Rodríguez se escindió de la UF y constituyó otra, la efímera Federación de Obreros y Empleados Ferroviarios que, si bien no representaba más de un 25\% de los afiliados del sector, consiguió por parte del gobierno de Roberto M. Ortiz, en forma expeditiva, la personería jurídica. El PC repudió estos movimientos "divisionistas" por parte de los dirigentes "apolíticos y prescindentes", que definía como "serviles" al gobierno; en especial, acusaba a Tramonti, Marotta y Silvetti. ${ }^{10}$

Incidían cada vez más las nuevas políticas del presidente Roberto M. Ortiz (1938-1942).

10. Fracasó la división de la Unión Ferroviaria (1 de julio de 1938)", Orientación, p. 2. 
El gobierno emitió un decreto en octubre de 1938 por el cual se impedía que los sindicatos tuvieran incumbencia en asuntos religiosos o políticos y se pudieran adherir a entidades que no estuviesen reconocidas como personas jurídicas. Era un intento por ejercer un control del movimiento obrero y por intentar aislar a los comunistas. Pero también afectaba la interna ferroviaria: intentaba aumentar las posibilidades de desarrollo de la "despolitizada" Federación de Obreros y Empleados Ferroviarios (lo cual resultó vano, pues ésta se reincorporó a la UF en marzo de 1940) y buscaba disciplinar a la UF, con la amenaza de quitarle su personería jurídica si se inmiscuía en cuestiones políticas. Al mismo tiempo, Ortiz nombró a Tramonti en la presidencia de la Caja de Jubilaciones Ferroviarias, iniciativa gubernamental condenada por el PC como una confirmación del intento por dividir y destruir la principal organización obrera del país. ${ }^{11}$

\section{El PC en el I Congreso cegetista}

La disyuntiva entre elegir por más prescindencia política o por salir completamente de ella y confluir con los partidos de izquierda, se volvió a plantear en ocasión del llamado Congreso por la Democracia y la Alianza de las Américas, realizado en Montevideo en marzo de 1939. En un debate que consumió tres días de discusiones a principios de ese mes, Domenech y un sector de la CA de la CGT planteó la oposición a enviar un delegado de la misma al cónclave, sosteniendo que éste era de carácter político. Pero dentro de la CA cegetista el

11. Pozzebón, S. Los divisionistas al servicio de las empresas y la reacción (8 de diciembre de 1938), Orientación, p. 8. sector comunista (representado por Chiarante) y la facción más adicta al PS (la encabezada por Pérez Leirós) sostenían lo contrario, entendiendo que la defensa de la democracia era un asunto político de importancia central para el movimiento obrero. Finalmente, se impuso la posición de no enviar delegado y en los meses que siguieron hasta julio de 1939, cuando debía sesionar el I Congreso de la CGT, ya completamente normalizada, hubo varias declaraciones del ferroviario Almarza, prosecretario de la central, y de la UF, a favor de mantener una "posición de neutralidad frente a cuestiones políticas".

Cumplida la gestión de dos años de Domenech como secretario general de la CGT, el balance mostraba, en junio de 1939, a una central orientada cada vez más a atender las reivindicaciones económicas y sociales del movimiento obrero, sin mayores preocupaciones por los planteos políticos. ${ }^{12}$ La CGT se preparaba para desarrollar su I Congreso ordinario, que debía completar su definitiva normalización. Los dos partidos de izquierda con fuerza en la central, el PS y el PC, definieron una línea de conciliación para dicho evento. Si bien tenían fuertes diferencias con el sector de Domenech, éste aún se mostraba consciente de necesitar el aporte de las fuerzas sindicales plenamente enroladas en ambos partidos. Este nuevo clima de acuerdo, que irrumpía y se agotaba una y otra vez, fue el que, finalmente, exhibió el congreso, realizado entre el 14 y el 16 de julio de 1939, en el local de la UF de la avenida Independencia. En los meses previos, los comunistas expresaron las grandes expectativas que les despertaba la realización del encuentro, apareciendo como defensores de la causa de la

12. Ver: CGT, Memoria y balance, 1937-1939, Buenos Aires, 1939. 
CGT y pugnando para que ésta se expandiera y se hiciera más potente. ${ }^{13}$

En esta ocasión las declaraciones públicas del partido excluían las críticas a la dirección cegetista y se dirigían todas a ratificar el espíritu unitario y componedor que acompañaba el evento, al que pretendía convertir en una caja de resonancia de sus políticas favorables a un frente democrático antifascista y antiimperialista. ${ }^{14}$ Los comunistas se preparaban para ocupar un lugar importante en la dirección de la central obrera y no querían malquistar ese paso con ninguna acción o declaración inconveniente. En este congreso, a diferencia del de 1936, los gremios orientados por el PC pudieron participar con todas las condiciones y gozar de todos los derechos. El albañil comunista P. Chiarante fue elegido uno de los siete dirigentes (en su caso, como secretario), para integrar la mesa de dirección del cónclave, que tuvo a Domenech como presidente y a Peréz Leirós como vicepresidente $1^{\circ}$. La constitución de esta mesa puede entenderse como expresión del equilibrio de fuerza existente entre las tres tendencias actuantes durante las deliberaciones: ferroviarios y sus aliados, socialistas y comunistas.

¿Cuál era el peso cuantitativo que los comunistas pudieron exhibir en el Congreso y cómo lo hicieron valer en el momento de definir las representaciones? La CGT usaba los datos de 1938 para establecer esta cuestión. Para ese entonces, la central poseía unos 280.000 afi-

13. Tomaron como bandera propia una consigna lanzada por Domenech: "Por 1.000.000 de afiliados a la CGT (9 de febrero de 1939)", Orientación, p. 7.

14. Peter, J. El congreso de la CGT: nuevo impulso hacia la unificación de todos los trabajadores (27 de abril de 1939), Orientación, pp. 7-11; y "Se inicia un gran congreso obrero” (13 de julio de 1939), Orientación, p. 3.

158 liados, pero los cotizantes regulares eran unos 166.000. Los gremios que tenían sus representantes en el CCC eran los que tenían un piso mínimo de unos 1500 cotizantes y ellos eran sólo doce, que agrupaban a 161.000 cotizantes. De éstos, según nuestros cálculos, ocho estaban bajo control de militantes socialistas y sindicalistas (Unión Ferroviaria, empleados de comercio, La Fraternidad, tranviarios, municipales, estatales, gráficos y cerveceros), uno que venía de tener una situación de paridad entre comunistas y socialistas, quedó en 1939 bajo mayoría del PC (la Unión Obrera Textil, con 3.700 cotizantes) y tres estaban bajo pleno dominio de los comunistas. En este último caso, se trataba de la FONC (con 30.000 cotizantes, algo menos de la mitad de los de la poderosa UF pero ubicado como el segundo sindicato del país en estos índices), la Federación Obrera de la Alimentación (con 2.500 cotizantes) y el SOIM (con unos 1.800 cotizantes). ${ }^{15} \mathrm{De}$ este modo, a los comunistas se les reconocía un control sobre cerca de 40.000 de los cotizantes que tenían representación en el CCC, es decir, casi un $25 \%$ de esta fuerza.

Una vez que la elección de las máximas autoridades fue realizada, los ferroviarios y sus aliados, más propensos a la línea prescindente, lograron hacer reelegir a Domenech como secretario general y aAlmarza como secretario adjunto, dominando, también, el resto del secretariado. Los socialistas pudieron colocar a varios de sus hombres en la dirección, por ejemplo, a sus dos figuras centrales, Pérez Leirós y Borlenghi, en la Comisión Administrativa y la Comisión Arbitral. Los comunistas, en tanto, consiguieron mantener a Chiarante como uno de los once integrantes de la Comi-

15. Libro de Actas del Comité Central Confederal de la CGT, reunión del 18 de diciembre de 1939, citado en Matsushita (1983, p. 162). 
sión Administrativa y a varios de sus cuadros obreros en el CCC como vocales: entre otros, José Peter (Federación Obrera de la Alimentación), Rubens Iscaro, Andrés Roca, Pedro Tadioli y Carlos Pérez (FONC), Juan Pavignano (SOIM) y Gelindo Pellichero (Unión Obrera Textil). ${ }^{16}$

Con estos resultados, los comunistas elaboraron un balance muy positivo del I Congreso de la CGT, destacando el clima "respetuoso" y "de concordia" que habría reinado en las deliberaciones, y el valor de algunas de definiciones y resoluciones aprobadas. ${ }^{17}$ Se comprometieron a un apoyo firme al plan de la CGT de alcanzar, en el período siguiente, el millón de afiliados, y que propiciara gestiones ante la USA y organizaciones gremiales autónomas para lograr la unidad en una sola central nacional. Pero las principales resoluciones por las que pugnaron los comunistas en ese congreso tenían que ver con cuestiones de política nacional e internacional: enfrentar lo que el PC definía como un peligroso curso de avance de la guerra y la reacción nazi-fascista. Así, los comunistas plantearon que la central obrera debía pronunciarse por: la defensa de las instituciones democráticas, la libertad de prensa, de palabra, de reunión y de asociación, la independencia de los pueblos, y la libertad de cultos; el combate contra el odio de raza o de nacionalidad, y por el triunfo de las ideas de paz, concordia mundial, democracia y justicia social (Iscaro, 1973, p. 240). Algunas de estas demandas, que eran compartidas por las delegaciones socialistas,

16. Quedó constituido el nuevo CCC de la CGT para el período 1939-1941 (28 de diciembre de 1939), Orientación, p. 5.

17. Contreras, $\mathrm{M}$. El congreso de la CGT: alta tribuna obrera (20 de julio de 1939), Orientación, p. 7. fueron aprobadas en el congreso, pero muchas de estas resoluciones apenas fueron recogidas.

Lo que cada vez más incidía en el debate político general y afectaba las definiciones globales de la CGT era la cuestión internacional y la inminente guerra que se avecinaba. Para los comunistas esto constituía un problema de primer orden. Desde el inicio de la estrategia del "Frente Popular" y, en especial, a partir de que la Alemania hitlerista y sus aliados profundizaron sus políticas de rearme y de exigencias de anexiones y reclamos territoriales, los comunistas habían colocado la denuncia al nazi-fascismo como uno de los ejes centrales de su propaganda, sobre todo, a partir de 1937 y 1938. Alertaban que el fascismo había dado una sucesión de "zarpazos": en Abisinia, en Austria, en España, en China y, finalmente, en Checoslovaquia; y criticaban las capitulaciones de los gobiernos inglés y francés, por no haber sido más firmes en enfrentar la prepotencia nazi. ${ }^{18}$ No sólo repudiaban las acciones expansionistas y racistas del régimen de Berlín en el mundo, sino, cada vez más, su presencia en el territorio nacional, a través de las empresas germanas aquí radicadas, la intervención de la embajada alemana y las acciones de personalidades y corrientes intelectuales y políticas partidarias de aquellos intereses y proyectos. Hasta mediados de agosto de 1939, estas caracterizaciones y políticas signaron la prensa comunista. ${ }^{19}$ En julio, el PC apoyó fervientemente un discurso del presidente Ortiz en una cena de camaradería de oficiales militares, por su "neto contenido democrático y antifascis-

18. La firmeza de las democracias salvará la independencia checa (1 de septiembre de 1938), Orientación, p. 1.

19. Por ejemplo: Complots en el país fomentaría el nazismo (10 de agosto de 1939), Orientación, III, p. 1. 
ta”, al denunciar el peligro nazi-fascista que se cernía sobre el mundo y el propio país. ${ }^{20} \mathrm{Con}$ esta línea, el permanente reclamo comunista era que la CGT asumiese posturas de repudio y combate a la Alemania nazi y los países del Eje. Así lo expresaron en el Congreso de la central. Lo inesperado llegó en agosto, cuando otra cuestión de política internacional gravitó decisivamente en las caracterizaciones y comportamientos del PC en la política nacional y, sobre todo, en el movimiento obrero y la CGT. ${ }^{21}$

\section{Los virajes de las estrategias cominternistas: del apoyo al pacto nazi-soviético a la unidad nacional antifascista}

El 23 de agosto de 1939 se produjo un imprevisto acontecimiento internacional: la firma de un pacto de no agresión germano-soviético, firmado por los cancilleres de ambos estados, von Ribbentrop y Molotov. Luego se conoció que el acuerdo contenía cláusulas secretas que establecían la delimitación de la zona de intereses en Europa oriental entre Alemania y la URSS, y el virtual reparto conjunto del territorio polaco. Pocos días después, tropas alemanas invadieron Polonia y comenzó la segunda guerra mundial. Todo esto provocó inmediatamente un replanteo de la política del "Frente Popular" en toda la IC: sus distintas secciones se orientaron hacia propuestas neutralistas, siguiendo las directivas moscovitas, condicionados por el convenio firmado con Alemania. La Comintern justificó el pacto como un aprovechamiento de las contradicciones entre

20. El discurso del Dr. Ortiz advierte sobre el peligro nazi-fascista (13 de julio de 1939), Orientación, p. 3.

21. Véase: Rapoport (1988). las potencias imperialistas, que logró romper la cadena de complicidades entre los Estados capitalistas, siempre dispuestos a aliarse para la destrucción de la Unión Soviética (Kriegel, 1985, pp. 143-145). E1 PC argentino, que se distinguía por una obediencia firme a los dictados de la URSS y la Comintern, adoptó igual camino, durante los veintiún meses en que éste se desplegó (Piemonte, 2014; Piro Mittelman, 2019). ${ }^{22}$ Justificó el tratado prácticamente desde el momento mismo de la firma, presentándolo como un triunfo soviético, que Stalin había impuesto a Hitler, y mediante el cual, este último no hacía más que reconocer el poderío de la URSS. ${ }^{23}$

El hasta ese momento impensado entendimiento germano-soviético y la rápida posición oficial del partido en su apoyo produjo cierta confusión en la militancia comunista. No es casual que Orientación, en el número siguiente al que informaba de las tratativas del acuerdo, hubiera dedicado buena parte de sus páginas a explicar el "verdadero motivo y carácter" de aquél, en respuesta a las acusaciones formuladas desde los gobiernos inglés y francés. ${ }^{24}$ En lo inmediato, el PC no abandonó la línea antinazi y felicitó a los polacos por la resistencia ofrecida a la invasión de la Wehrmacht. Al mismo tiempo, continuó sosteniendo la necesidad de que los planteos antihitlerianos se plasmaran en suelo nacional: "no debemos permitir que los nazis operen en nuestro país". ${ }^{25} \mathrm{El}$ giro

22. Este período es completamente ocultado por las historias oficiales: Partido Comunista, Comisión del Comité Central (1947); Arévalo (1983).

23. La URSS por la paz (24 de agosto de 1939), Orientación, p. 1.

24. La verdad sobre el pacto ruso-alemán (31 de agosto de 1939). Orientación, p. 1.

25. Aplastar al nazismo (7 de septiembre de 1939). 
mayor sobrevino cuando, tras la ocupación de partes de Polonia por tropas rusas, los comunistas comenzaron a predicar una "política de paz" y de repudio a la "guerra imperialista". De este modo, el PC empezaba a propiciar la línea de la "neutralidad": "La proposición de paz que contiene el nuevo convenio ruso-germano, respaldado por la Unión de Repúblicas Soviéticas, ha encontrado un profundo eco en los pueblos de todo el mundo, y en primer término en los pueblos de los países beligerantes. Las masas quieren la paz". ${ }^{26}$ Durante octubre de 1939, los dirigentes comunistas escribieron artículos en Orientación, tratando de justificar la nueva consigna partidaria de "paz justa y democrática”. Un mes después, debieron dedicarse a fundamentar la invasión soviética a Finlandia, negando que Moscú quisiera afectar la integridad nacional de aquel país, sino sólo proteger las fronteras rusas y la seguridad de la ciudad de Leningrado. ${ }^{27}$ La misma justificación se usó para la anexión soviética de los países bálticos.

La política de la neutralidad y de denuncia de la "guerra imperialista" que sostenía el PC lo colocaba en un debate cada vez más abierto con el PS, con el que compartía espacios comunes en la estructura gremial. Comenzó a desatarse una disputa por los pronunciamientos de los sindicatos y de la CGT en torno al tema. En las asambleas de algunos sindicatos, se votó en contra del pacto (por ejemplo, en la Unión Obrera Textil (en adelante, UOT), a pesar de que la dirección la tenía el PC). En el seno de la CGT la polémica entre socialistas y comunistas fue particularmente dura. Las

Orientación, p. 1.

26. Se impone la política pacifista de la URSS (5 de octubre de 1939). Orientación, p. 1.

27. Finlandia, pretexto para azuzar la provocación contra la URSS (30 de noviembre de 1939). Orientación, p. 1. fuertes querellas entre socialistas y comunistas por el tema de la guerra introdujeron un nuevo eje de conflicto en el seno de la CGT, quedando relativamente atemperado el anterior, entre el bloque apolítico y prescindente de la dirección de Domenech y el ala de los cuadros gremiales vinculados al PS y PC, que pugnaban por mayores definiciones políticas democráticas y antifascistas a la central. Ahora, la discordia socialista-comunista distraía esa anterior discusión. En un sentido, ello benefició coyunturalmente a los sectores que abogaban por la prescindencia, al mostrar que ese tipo de debates dividían a las organizaciones obreras y que, por ello, había que sólo concentrarse en las cuestiones "estrictamente sindicales". Todo esto condujo a cierta parálisis en el accionar de la CGT. No hubo posibilidad de acuerdo en torno a un acto conjunto para el 1 de mayo en 1940. Las rencillas se agudizaron días después, en la reunión del CCC del 16 de mayo de 1940, convocado para tratar la situación internacional con el inicio de la guerra mundial. Durante toda la segunda mitad de ese año, la acción cegetista y de sus principales gremios, quedó muy afectada por los entreveros que socialistas y comunistas tuvieron acerca de la posición a adoptar frente a la guerra.

Iniciado el año 1941, las cosas no mejoraron. Volvieron a fracasar las negociaciones para concretar un gran acto unitario de la CGT para el 1 de mayo. Domenech y sus seguidores en la dirección, se refugiaban con más empeño en actitudes "sindicalistas" y apolíticas, a la vez que los dos grandes partidos de izquierda no alcanzaban a definir una caracterización común frente a los acontecimientos bélicos que sacudían al mundo y al propio país. El PS lanzó su convocatoria a un acto propio y la dirección cegetista se abstuvo de realizar un llamado a un acto conjunto de la CGT y los partidos 
“obreros" y "democráticos", dejando al PC sin posibilidades de plasmar su política "unitaria". Las polémicas internas, sin embargo, no habían ocasionado un debilitamiento numérico de la central, la más poderosa organizaciónque había dado el movimiento obrero argentino hasta ese momento. $\mathrm{El}$ ingreso y desarrollo de los sindicatos industriales y de la construcción dirigidos por los comunistas, que eran los que poseían las mayores tasas de aumento de afiliados y cotizantes, fortaleció mucho a la CGT. En 1941 el DNT realizó un nuevo censo gremial, en donde se verificó esa expansión de los activos cegetistas. En los cinco años transcurridos entre 1936 y 1941, el total de trabajadores afiliados a sindicatos en el país evolucionó de unos 370.000 a unos 473.000. La CGT fue la más favorecida por ese proceso, pues creció de 262.630 afiliados a 311.076. La USA se debilitó levemente, al perder unos 2.000 adherentes de los ya escasos 25.000 que tenía antes; mientras que la FACE (organizaciones católicas) y los sindicatos autónomos aumentaron de 8.012 afiliados a 18.675 y de 72.834 a 120.038 , respectivamente. ${ }^{28}$

El dato a destacar era el gran incremento de los sindicatos dirigidos por los comunistas. Durante esos años, el partido fue asegurando su hegemonía sobre los gremios pertenecientes al área industrial y de la construcción, que se vieron implicados en constantes huelgas y conflictos laborales. Logró imponer a sus cuadros como secretarios generales de los seis sindicatos más importantes en aquellos espacios: los mencionados casos de la Construcción, de

28. Datos extraídos de: Ministerio del Interior, Departamento Nacional del Trabajo, División de Estadísticas, Organización sindical. Asociaciones obreras y patronales, Serie B (Estadísticas y Censos) N ${ }^{\circ}$ 9, Buenos Aires, 1941. Biblioteca Tornquist. Banco Central de la República Argentina, Buenos Aires.

162 la Industria de la Carne, de la Industria Metalúrgica, Textil, del Vestido y, posteriormente, de la Madera. Esas y otras organizaciones sindicales dirigidas por los comunistas superaban los 100 mil afiliados hacia principios de los años cuarenta. Ello se hacía en un contexto muy dificultoso para el accionar del partido, en medio de un anticomunismo cada vez más desembozado (López Cantera, 2016/2017). Bajo el gobierno de Ramón S. Castillo (19421943), continuaron las medidas represivas a dicho partido, en especial, en el terreno sindical. En 1941, el Poder Ejecutivo Nacional dictó el decreto $\mathrm{N}^{\circ} 31.321$ y el de la Provincia de Buenos Aires el $\mathrm{N}^{\circ} 111$, que tuvieron la finalidad de limitar la libertad sindical en general, pero especialmente, dificultar el accionar de los comunistas. El PC hizo una denuncia abierta de estos decretos. A través de ellos, el Estado tendió a no reconocer el nivel de representatividad de los gremios comunistas (específicamente, esto rigió para los casos de la FONC y la UOT), negándose el DNT a mantener relaciones con sus dirigentes, aduciendo que éstos eran "comunistas prontuariados que, lejos de tener una actuación sindical normal, en beneficio de la clase obrera, se hallan encauzados en una corriente política anarquizante, tratando de toda forma de desviar el movimiento sindical obrero para hacerlo servir a su ideología política" (Iscaro, 1973, p. 241). Sin embargo, estos sindicatos no dejaron de procurar entablar relaciones con el Estado y de aceptar e, incluso, solicitar la intervención del DNT.

El realineamiento de posiciones política en el interior de la CGT cambió una vez más, y de manera brusca, el 22 de junio de 1941, cuando se produjo un nuevo giro fundamental en el curso de la Segunda Guerra Mundial: Alemania invadió a la URSS sin declaración previa. Superada la conmoción inicial, el PC abando- 
nó la anterior estrategia neutralista y se comprometió a la denuncia global del nazi-fascismo, a la solidaridad activa con la URSS y a una orientación de acuerdo total con los "aliados" (países capitalistas democráticos), lo que llevó a retomar, en forma aún más profunda que antes, la línea del "Frente Popular". Esto es lo que comenzó a plantearse en la Conferencia de la regional Capital del partido en septiembre de 1941 y, especialmente, en el X Congreso Nacional del PC en noviembre del mismo año. ${ }^{29}$ Desde entonces, la estrategia del partido se sustentó en el objetivo de conformar un amplio "frente democrático nacional antifascista", con distintas fuerzas políticas, sindicales, sociales y civiles. ${ }^{30}$ Esta línea definió de allí en más la actuación del PC en todos sus frentes, desde el político hasta el cultural, desde el sindical hasta el femenino (Cane, 1997; Valobra, 2015).

En este nuevo contexto, dentro de la CGT quedaron a un lado las viejas disputas entre socialistas y comunistas por la cuestión de la guerra, al encontrarse otra vez un punto de acuerdo en torno al contundente apoyo al campo aliado y a la causa del antifascismo y la democracia. Ello volvió a reposicionar el tradicional enfrentamiento entre, por un lado, los sectores partidarios de posturas firmemente políticas (los militantes del PC y los más asociados a la estructura del PS) y, por el otro, los defensores de la autonomía gremial frente a los partidos y las concepciones apolíticas, neutralistas y prescindentes. Entre estos últimos se hallaban tanto los provenientes de la histórica corriente

29. Los discursos y documentos del congreso en: Arnedo Álvarez (1941); Giudici (1941); Real (1941).

30. Durante esos meses, salieron publicados muchos folletos de los dirigentes comunistas, para reordenar a las fuerzas partidarias en torno a la "unidad nacional antifascista”. Entre otros: Codovilla (1941). sindicalista, como también varios de origen socialista, que se habían emancipado del control partidario y habían elegido un repliegue a sus atribuciones puramente gremiales, incluso si ello conducía a un distanciamiento concreto con las necesidades u orientaciones de su propio partido (Ceruso, 2019; Herrera, 2019).

Para el PC volvía a cobrar fuerza la pelea frontal con la conducción mayoritaria de la CGT, es decir, con el sector dirigido por Domenech y Almarza. El dilema era bastante obvio: mientras el líder cegetista persistía en la postura prescindente y apolítica de la central, el PC, desde el ingreso de la URSS a la guerra, pugnaba por armar una amplia coalición "democrática" contra el fascismo y la reacción, en la que pretendía incorporar no sólo a todos los partidos que pudieran estar en sintonía con esta estrategia, sino también (y especialmente) a la CGT. El PC comenzó a forzar a la central a que asumiera definiciones claras en torno a la política nacional, pero la corriente agrupada alrededor de Domenech cada vez se oponía más a ello. Así ocurrió con respecto al estado de sitio, declarado desde diciembre de 1941: para los comunistas era el momento de salir a denunciarlo por su carácter pro-fascista; para Domenech y su tendencia la medida lanzada por el Ejecutivo no afectaría mayormente al movimiento obrero, en tanto éste se limitara a sus funciones específicas.

\section{Los comunistas en el CCC y el II Congreso de la CGT de 1942: hacia una nueva ruptura de la CGT}

A medida que el conflicto entre los comunistas y Domenech se profundizaba, la CGT fue perdiendo toda posibilidad de entablar un 
debate en su seno. Luego de la acalorada reunión de mayo de 1940 antes mencionada, el CCC estuvo dos años sin reunirse (a pesar de que estatutariamente debía hacerlo cada cuatro meses). Fue recién 28 meses después, el 13 de octubre de 1942, cuando volvió a efectuarse una reunión de este tipo, convocatoria en la que se debía fijar la fecha del II Congreso ordinario de la central obrera. La ocasión sirvió para el desarrollo de una disputa aún mayor entre los representantes sindicales del PC y los miembros de la dirección mayoritaria de la CGT, quienes era cada vez más definidos por ese partido como sindicalistas "amarillos". Buena parte del encuentro se lo llevó una discusión administrativa (surgida a partir de un atraso de las cotizaciones de la Federación Gráfica Bonaerense, que podía permitir la exclusión de su miembro representante en el CCC), lo que derivó en un conflicto abierto entre ciertos gremios y el Secretariado. En verdad, lo que encubría esta discusión era una disputa clara entre los gremios comunistas y también los más vinculados al PS frente a los de la corriente de Domenech que dominaban dicho Secretariado.

En esa oportunidad, los comunistas presentaron un duro documento contra la conducción cegetista. Hacían responsable al Secretariado y a la mayoría de la CA de haber adoptado métodos burocráticos para arrastrar a la central al “'neutralismo político', a un aislamiento suicida, a una despreocupación por los problemas políticos, a una inercia y a un desentendimiento que sólo puede favorecer a los enemigos de la clase obrera, que sólo beneficia a la oligarquía pronazi y a la quinta columna hitlerista", todo "en flagrante contradicción con el espíritu que guía a la clase obrera". Los representantes del PC acusaban a los dirigentes de la CGT de haber abandonado el apoyo a la lucha de los pueblos contra el nazifascismo. También les reprochaban no haberse comprometido a una oposición franca contra las restricciones de la libertad sindical y de los derechos democráticos impuestas por el gobierno de Castillo; de levantar una política pro-oficialista y contraria a la formación del "movimiento de unidad nacional"; de negarse a las convocatorias a la acción común hechas por la USA y el PS; de haber "defraudado las más elementales normas de la democracia sindical", instaurando "una situación de facto" e ignorando "la experiencia que culminó el 12 de diciembre de 1935". ${ }^{31}$

En contraposición al curso impreso por la dirección vigente, los comunistas planteaban la necesidad de estructurar una acción distinta para la CGT

Una acción digna de la más grande central obrera del país que signifique la movilización permanente del proletariado en conjunto con todas las fuerzas democráticas, mancomunadas en un gran movimiento de unión nacional para defender nuestras instituciones democráticas y recuperar el pleno goce de las libertades cívicas (...) Una acción que, impulsada con vigor desde nuestra Confederación, de acuerdo con las resoluciones de nuestro Congreso de julio de 1939, signifique el aplastamiento de la quinta columna hitlerista en el país. ${ }^{32}$

31. Actas de las reuniones del Comité Central Confederal, efectuadas en mayo de 1940 y en octubre de 1942. Confederación General del Trabajo de la República Argentina, Buenos Aires, 1942. Centro de Documentación e Investigación de la Cultura de Izquierdas (CeDInCI), Buenos Aires.

32. Actas de las reuniones del Comité Central Confederal, efectuadas en mayo de 1940 y en octubre de 1942. Confederación General del Trabajo de la República Argentina, Buenos Aires, 1942. CeDInCI 
En aquella reunión del CCC de octubre de 1942, los representantes comunistas, aliados a la corriente de gremialistas socialistas liderada por el municipal Pérez Leirós lograron imponerle a ese organismo la adopción de dos resoluciones políticas generales. En una, se lanzó una exhortación al gobierno para que el país efectúe la ruptura de relaciones con Alemania, Italia y Japón. En la otra, se declaró la adhesión de la central a la formación de una "Unión $\mathrm{Na}$ cional Democrática”; se denunció la violencia, el fraude electoral y las "inmoralidades administrativas carentes de sanciones ejemplificadoras"; y se abogó por la eliminación de las restricciones a las libertades, derechos y garantías, trabadas por el estado de sitio, y por el restablecimiento de la normalidad institucional.

Una nueva y más grave situación de enfrentamiento interno se produjo durante el II Congreso de la CGT, que sesionó entre el 15 y el 19 de diciembre de 1942, con la participación de 142 delegados. Los comunistas ya se habían percatado que entre sus representantes y los más vinculados a la estructura del PS formaban una mayoría para lograr desplazar a Domenech como Secretario General de la central. La primera prueba ocurrió con la elección del presidente y vicepresidente del cónclave: la alianza sindical socialista-comunista obtuvo una victoria rotunda: 117.713 votos fueron para la candidatura a presidente del dirigente socialista de los empleados de comercio Angel Borlenghi y 108.082 para la candidatura a vice del dirigente comunista del gremio de la construcción Pedro Chiarante. Domenech logró 60.069 votos para presidente (prácticamente sólo los votos de los delegados de la UF); tras esta derrota, se retiró del congreso, sin rendir cuenta de su actuación como Secretario General en el período que culminaba. La memoria y el balance de la conducción fueron defendidas por otros miembros de su grupo, que permanentemente amenazaban con irse de la reunión, en medio de discusiones.

Para los comunistas, el balance del congreso era muy auspicioso: "El balance político del Congreso ha sido positivo, porque adoptó importantes resoluciones y afirmó la voluntad unitaria de los trabajadores, condenando al mismo tiempo, métodos y prácticas aplicadas en nuestra central, que habían provocado un general descontento entre las organizaciones filiales". ${ }^{33}$ Iscaro destacaba la elección de Borlenghi en la presidencia del congreso y de Chiarante como vicepresidente del mismo. Entendía que eso representaba una muestra de la unidad y, a la vez, de sanción a los que impusieron una línea de debilidad, prescindencia y exclusiones en la CGT. También informaba que el congreso había hecho un inventario muy crítico de la gestión anterior de la central, en varios temas: se condenó la omisión de la convocatoria al congreso en el plazo correspondiente y la injustificable demora en la citación del CCC, que no se reunió durante 8 meses. Asimismo, se congratulaba que el Congreso hubiese aprobado las resoluciones del CC sobre ruptura de relaciones con los países del Eje, y en apoyo a la "Unidad Nacional". Por último, señalaba:

El discurso de clausura del Congreso, a cargo del camarada Borlenghi, que mereció general aprobación, por los elevados conceptos unitarios emitidos, merece destacarse especialmente cuando afirmó el derecho que tienen los comunistas de actuar en la CGT y de no ser excluidos de la dirección de la misma. Afirmó que la CGT no puede ser comunista. Debe ser una CGT para toda

33. Iscaro, R. El reciente congreso de la Conf. General del Trabajo (24 de diciembre de 1942), Orientación, p. 1. 
la clase obrera organizada, en la que todos se sientan cómodos". ${ }^{34}$

Los dirigentes gremiales comunistas (Chiarante, Iscaro, Kaner, Burgas y Peter, entre otros) tuvieron una participación decisiva en este cónclave, integrando y ejerciendo un rol preponderante en casi todas las comisiones. Muchas de las resoluciones aprobadas formalmente por la central en el evento fueron promovidas especialmente por los comunistas $\mathrm{y}$ estuvieron a tono con sus preocupaciones, aunque luego tuvieron poca efectividad. La principal de ellas fue la de que el CCC de la CGT apoye a la "unidad nacional democrática" y realice tratativas con los partidos y organizaciones gremiales, económicas y culturales de "filiación democrática" tendientes a constituir una entidad coordinadora de dicha unidad. El PC por esa época estaba obsesionado con la creación del "frente democrático antifascista", especialmente por el advenimiento de las próximas elecciones presidenciales (en las que pretendía conformar una coalición electoral que enfrentase a la candidatura oficialista de Robustiano Patrón Costas), y repudiaba la orientación "prescindente" que en este sentido se había impuesto la dirección de Domenech.

En otras resoluciones del congreso se planteó que la conducción cegetista luchara por un plan de evidente contenido político: la realización de gestiones ante el Poder Ejecutivo Nacional y el Parlamento Nacional para lograr el levantamiento del estado de sitio; la intensificación de campaña de agitación contra la carestía de la vida, por aumentos salariales y por la sanción de iniciativas parlamentarias que impusieran el salario mínimo para los trabajadores de todo el país; el despliegue de tareas tendientes a con-

34. Iscaro, R. El reciente congreso de la Conf. General del Trabajo (24 de diciembre de 1942). Orientación, p. 2. quistar los derechos políticos para la mujer; el fomento al desarrollo de la industria argentina; el mantenimiento de relaciones con el Comité Sindical Anglo-Soviético y la Confederación de Trabajadores de América Latina (CTAL); el pronunciamiento a favor de la ruptura de relaciones con los países del Eje y por la reanudación de los vínculos diplomáticos con la URSS; la firme oposición a la ley 4.144; y, por último, la promoción de la educación y el esparcimiento de los trabajadores a través de una universidad y un turismo obreros (Iscaro, 1973, pp. 249-250). Era un programa acorde con los planteos políticos que venía sosteniendo el PC.

En la primera quincena de 1943, según resolución del congreso, debía constituirse el nuevo CCC de la CGT, en el que tenía que designarse la Comisión Directiva y el Secretariado de la central. Fue en esa reunión que el conflicto estalló en forma irrefrenable y condujo a la división de la central, la segunda, luego de la ocurrida en diciembre de $1935 .{ }^{35} \mathrm{La}$ primera dificultad surgió al intentar concertar la forma de la elección de los delegados de cada sindicato al CCC. En los estatutos ya estaba estipulado que el número de éstos se definía de acuerdo a la cantidad de cotizantes de cada organización. Históricamente, era la UF, el gremio más numeroso de la CGT y del que habían provenido siempre los secretarios generales de la misma, la que definía las elecciones en el CCC, pues un 40\% de los delegados le pertenecían. En los sindicatos comunistas se eligieron a estos representantes por el voto general y secreto de los afiliados de cada gremio, y se propuso, infructuosamente, que se adopte igual mecanismo en los demás sindicatos. Pero

35. Este proceso de crisis y división de la CGT está reconstruido en algunas historias militantes del movimiento obrero: Oddone (1949, p. 383 y ss.) y López (1971, pp. 363-372). 
en las organizaciones agrupadas en la corriente de Domenech y también en las del sector más vinculado al PS, fueron las comisiones directivas de cada sindicato las que designaron a sus representantes. Domenech decidió dar un paso más y exigió a todos los delegados al CCC de su gremio, la UF, que se comprometieran por escrito a que en su totalidad apoyarían la reelección de él como Secretario General de la CGT (incluso, dos de ellos que se opusieron a este criterio fueron cambiados por la CD del gremio).

Cuando llegó el momento de la elección de la conducción cegetista, se advirtió claramente una relación de fuerzas más o menos equilibrada entre las distintas corrientes político-sindicales. Los comunistas disponían de la representación de los principales sindicatos industriales y de la construcción ya mencionados. Los gremios claramente vinculados al PS eran cuatro: empleados de comercio, municipales, del Estado y fraternales, y sus figuras claves eran Ángel Borlenghi y Francisco Pérez Leirós. Los socialistas y sindicalistas de Domenech, en tanto, dominaban tres organizaciones: UF, tranviarios y cerveceros. Este sector conformó la lista $\mathrm{N}^{\circ} 1$.

Los socialistas de Borlenghi y Pérez Leirós se vieron, entonces, obligados a tejer un acuerdo con los comunistas, que se habían convertido en la pieza decisiva para definir la interna de la central. Les ofrecieron un lugar clave en una nueva conducción cegetista pero argumentando que esta debía ser mayoritariamente socialista, pues el gobierno y el empresariado no aceptarían una CGT de dirección comunista. El PC aceptó este criterio, y así se constituyó la lista $\mathrm{N}^{\circ} 2$. No obstante, parecía estar claro que, con la enorme representación del sindicato ferroviario, Domenech se aseguraba la reelección. Hecho el escrutinio, sin embargo, se advirtió que un delegado de este último gremio, contrariando el "compromiso escrito" de votar por Domenech, sufragó por la lista $\mathrm{N}^{\circ} 2$. La lista $\mathrm{N}^{\circ} 1$ entonces desconoció la votación y decidió reemplazar al delegado ferroviario "díscolo" por otro "leal". La lista $\mathrm{N}^{\circ} 2$ lo encontró inaceptable. La reunión se partió entre los dos sectores, surgiendo las dos CGTs, reconocidas por el número de la lista. Pérez Leirós fue elegido secretario general de esa $\mathrm{CGT} \mathrm{N}^{\circ} 2{ }^{36}$

E1 PC sacó un juicio lapidario sobre el sector liderado por Domenech: "La Confederación General del Trabajo acaba de cerrar en su existencia un ciclo cuya característica fue el predominio en su dirección de un grupo divisionista, antiobrero y antidemocrático. El mantenimiento de ese grupo en los puestos de comando entraba en colisión, ya no solamente con los intereses esenciales de la clase trabajadora, sino también con la madurez orgánica y política alcanzada por ésta. El profundo abismo entre el programa antiobrero y anticegetista del grupo divisionista Domenech-Almarza y el nivel de organización y de conciencia desarrollado por la clase obrera, determinaron el aislamiento y descalificación de ese grupo que pretendía imponer al movimiento sindical los senderos marcados por la reacción". ${ }^{37}$ Ahora los comunistas llegaban a la dirección de la central, pero de una central dividida y por lo tanto debilitada.

36. La visión del PC: Francisco Pérez Leirós, nuevo secretario de la CGT (11 de marzo de 1943), Orientación, p. 1.

37. Por una CGT unitaria y antinazi se pronuncia la clase trabajadora de toda la república (8 de abril de 1943), Orientación, p. 1. 


\section{Conclusiones}

Durante buena parte de 1939, el PC mantuvo un frente de hecho con los sectores cegetistas más orgánicos al PS con el fin de hacer orbitar a la central en el gran "Frente Popular" antifascista de oposición, junto a los partidos de izquierda y democráticos. Ello se verificó con claridad en el Congreso de la central de julio de aquel año. En contra de ello actuaba el sector liderado por Domenech que propugnaba una línea de prescindencia política, sindicalismo autónomo y reformismo pragmático alejado de cualquier influencia partidaria. A partir de agosto-septiembre de aquel año y hasta mediados de 1941, si bien se mantuvo la división de esos dos campos dentro de la CGT, se operó una modificación en uno de ellos, que pareció atemperar esa contradicción fundamental. En efecto, los gremialistas que seguían las directivas partidarias y procuraban una mayor definición política de la organización, se dividieron agriamente. Ello ocurrió cuando el PC, a partir del apoyo al Pacto nazi-soviético, decidió propiciar la política del neutralismo en la guerra. Reemplazada esa línea en julio de 1941, con motivo del ingreso de la URSS a la conflagración mundial y a la alianza militar y política antifascista, retornó la posibilidad de un acuerdo entre socialistas y comunistas dentro de la CGT, reiniciándose así el viejo enfrentamiento con las tendencias antipolíticas y sindicalistas que aún dirigían a la central. El congreso de fines de 1942 y los eventos de los meses siguientes de 1943, muestran la vigencia de esa articulación de dos campos dentro de la confederación. Lo cierto es que en ambos terrenos el principio de autonomía sindical y política de la clase trabajadora aparecía tensionado por una dinámica que en los hechos lo cuestionaba: por un lado, por la orientación neutralista y prescindente del sindicalismo, que bloqueaba la ar- ticulación política del movimiento obrero; por el otro, por la estrategia frentepopulista y de unidad antifascista propiciada por comunistas y socialistas, que pretendía ubicar a los trabajadores y a sus partidos como parte de una asociación común con sectores de la burguesía democrática. La ruptura y conformación de dos CGT es el resultado del proceso analizado y el preanuncio de los dos bloques de apoyo a coaliciones en los que se dividirá el movimiento obrero frente a la emergencia del peronismo, a partir de 1944-1945. 


\section{Referencias Bibliográficas}

Arévalo, O. (1983). El Partido Comunista. Buenos Aires: Centro Editor de América Latina.

Aricó, J. (1979). Los comunistas en los años treinta. Controversia, 2-3 (suplemento nº 1), México, v-vii.

Arnedo Álvarez, G. (1941). La Unión Nacional garantía de la Victoria. Informe rendido ante el X Xongreso del Partido Comunista, realizado en Córdoba los días 15, 16 y 17 de noviembre de 1941, Buenos Aires: Ediciones del CC del PC.

Bisso, A. (2000). El antifascismo argentino: imagen de redención "democrática" de la sociedad civil en la Argentina fraudulenta y militar de los años 30 y 40. Trabajos y Comunicaciones, 26-27, 211-232. Recuperado de http://www.memoria.fahce.unlp.edu.ar/art_revistas/pr.13/pr.13.pdf

Bisso, A. (2007). El antifascismo argentino. Selección documental y estudio preliminar. Buenos Aires: CeDInCI Editores/Buenos Libros.

Broué, P. (1997). Histoire de l'Internationale Communiste, 1919-1943. Paris: Fayard.

Camarero, H. (2007). A la conquista de la clase obrera. Los comunistas y el mundo del trabajo en la Argentina, 1920-1935. Buenos Aires: Siglo XXI Editora Iberoamericana.

Camarero, H. (2013). La estrategia de clase contra clase y sus efectos en la proletarización del Partido Comunista Argentino, 1928-1935. En C. Aguirre (Comp.), Militantes, intelectuales y revolucionarios. Ensayos sobre marxismo e izquierda en América Latina, (pp. 21-50). Raleigh, North Carolina (USA): North Carolina State University and A Contracorriente.

Camarero, H. (2015). La CGT en disputa. Prescindencia apolítica de la dirección sindicalista y frentepopulismo comunista, 1935-1939. Cuadernos del Ciesal, 14, 35-58. Recuperado de https:// ri.conicet.gov.ar/handle/11336/45527

Camarero, H. (2017). Tiempos rojos. El impacto de la Revolución rusa en la Argentina. Buenos Aires: Sudamericana.

Camarero, H. (2018). Comunismo, peronismo y movimiento obrero en la Argentina durante la primera mitad del siglo XX. Un abordaje histórico-sociológico. En H. Camarero y M. Mangiantini (Eds.), El movimiento obrero y las izquierdas en América Latina: experiencias de lucha, inserción y organización (pp. 1-23), vol.2. Raleigh, North Carolina (USA): The University of North Carolina Press/ A Contracorriente.

Cane, J. (1997). 'Unity for the Defense of Culture': The A.I.A.P.E. and the Cultural Politics of Argentine Antifascism, 1935-1943. Hispanic American Historical Review, 77(3), Duke University Press, 443-482.

Carr, E. H. (1986). El ocaso de la Comintern, 1930-1935. Madrid: Alianza.

Ceruso, D. (2015). La izquierda en la fábrica. La militancia obrera industrial en el lugar de trabajo, 1916-1943. Buenos Aires: Imago Mundi (ColecciónArchivos). 
Ceruso, D. (2017a). El Partido Socialista y la cuestión gremial. Debates internos durante la primera mitad de la década infame. Archivos de historia del movimiento obrero y la izquierda, 10,119-139. Recuperado de https://www.archivosrevista.com.ar/numeros/index.php/archivos/article/view/23

Ceruso, D. (2017b). El Partido Socialista y el movimiento sindical tras la conquista de la Confederación General del Trabajo (1935-1937). Páginas, revista digital de la Escuela de Historia, 20, 131-146. Recuperado de http://revistapaginas.unr.edu.ar/index.php/RevPaginas/article/view/263/html

Ceruso, D. (2019). El vínculo entre las izquierdas y el movimiento obrero. Un análisis de la experiencia del Partido Socialista argentino en los últimos años de la década de 1930. Nuevo Mundo Mundos Nuevos [En ligne], Débats, mis en ligne le 11 juin 2019. https://doi.org/10.4000/nuevomundo.75901

Claudín, F. (1970). La crisis del movimiento comunista. Tomo I: De la Komintern al Kominform. Madrid: Ruedo ibérico.

Cheresky, I. (1984). Sindicatos y fuerzas políticas en la Argentina preperonista (1930-1943). En P. González Casanova (Coord.), Historia del movimiento obrero en América latina (pp. 147-199), vol. 4. México: Siglo XXI.

del Campo, H. (1983). Sindicalismo y peronismo. Los comienzos de un vinculo perdurable. Buenos Aires: CLACSO.

Di Tella, T. S. (2003). Perón y los sindicatos. El inicio de una relación conflictiva. Buenos Aires: Ariel.

Codovilla, V. (1941). Unidos para aplastar al monstruo fascista. Buenos Aires: Problemas.

Codovilla, V. (1984) Fascismo, democracia y frente popular. VII Congreso de la Internacional Comunista. México: Pasado y Presente.

García, L. (2017). En torno al concepto de 'prescindencia': la corriente sindicalista al frente de la CGT (1930-1935). Archivos de historia del movimiento obrero y la izquierda, 10, 95-115. Recuperado de https:// www.archivosrevista.com.ar/numeros/index.php/archivos/article/view/33

Giudici, E. (1941). Los comunistas en la defensa de la legalidad democrática. Buenos Aires: Ediciones del CC del Partido Comunista.

Godio, J. (1989). El movimiento obrero argentino (1930-1943). Socialismo, comunismo y nacionalismo obrero. Buenos Aires: Legasa.

Hájek, M. (1984). Historia de la Tercera Internacional. La politica de frente único (1921-1935). Barcelona: Crítica.

Herrera, C. M. (2019). En vísperas del diluvio. El gremialismo socialista ante la irrupción del peronismo. Buenos Aires: Grupo Editor Universitario.

Horowitz, J. (2004). Los sindicatos, el Estado y el surgimiento de Perón, 1930-1946. Buenos Aires: Eduntref. 
Iñigo Carrera, N. (2000). La estrategia de la clase obrera, 1936. Buenos Aires: La Rosa Blindada. PIMSA.

Iscaro, R. (1973). Historia del movimiento sindical. Buenos Aires: Fundamentos.

Kriegel, A. (1985). La Tercera Internacional. En J. Droz (Dir.), Historia general del socialismo. De 1918 a 1945. Barcelona: Destino.

Korzeniewicz, R. (1993). Las vísperas del peronismo. Los conflictos laborales entre 1930 y 1943. Desarrollo Económico. Revista de Ciencias Sociales, 131,323-354.

López, A. (1971). Historia del movimiento social y la clase obrera argentina. Buenos Aires: Programa.

López Cantera, M. (2016/2017). El anticomunismo argentino entre 1930 y 1943. Los orígenes de la construcción de un enemigo. The International Nerwsletterof Communist Studies Online, 29-30, 71-80. Recuperado de https://ri.conicet.gov.ar/handle/11336/52456

Matsushita, H. (1983). Movimiento obrero argentino, 1930-1945. Sus proyecciones en los origenes del peronismo. Buenos Aires: Siglo veinte.

Oddone, J. (1949). Gremialismo proletario argentino. Buenos Aires: La Vanguardia.

Partido Comunista, Comisión del Comité Central (1947). Esbozo de Historia del Partido Comunista de la Argentina. Buenos Aires: Anteo.

Piemonte, V. A. (2014). El Partido Comunista de la Argentina ante la Segunda Guerra Mundial y la disolución de la Internacional Comunista, 1939-1943, Pacarina del Sur. Revista del pensamiento crítico latinoamericano, 18,1-40. Recuperado de https://ri.conicet.gov.ar/handle/11336/33257

Piro Mittelman, G. (2019). El giro neutralista del Partido Comunista argentino y los efectos sobre su alianza con el Partido Socialista (1939-1941). Archivos de historia del movimiento obrero y la izquierda, 14,141161. Recuperado de https://www.archivosrevista.com.ar/numeros/index.php/archivos/article/view/70

Rapoport, M. (1988). Los partidos de izquierda, el movimiento obrero y la política internacional (1930-1946). Buenos Aires: Centro Editor de América Latina.

Real,J.J.(1941). Nuestra fuerza y nuestras debilidades. Informe rendido ante el $X^{\circ}$ Congreso del Partido Comunista, realizado en Córdoba los días 15, 16 y 17 de noviembre de 1941. Buenos Aires: Ediciones del CC del PC.

Tosstorff, R. (2018). The Red International of Labour Unions (RILU), 1920-1937. Chicago: Haymarket Books.

Valobra, A. (2015). Formación de cuadros y frentes populares: relaciones de clase y género en el Partido Comunista de Argentina, 1935-1951. Revista Izquierdas.cl, 23, 127-156. Recuperado de http://www. izquierdas.cl/images/pdf/2015/n23/art07.pdf 